\title{
A EXPERIÊNCIA VIVIDA DE MULHERES NA CONJUGALIDADE CONTEMPORÂNEA: UMA PERSPECTIVA FENOMENOLÓGICO-EXISTENCIAL
}

\author{
The women's lived experience in contemporary conjugality: a phenomenological-existential \\ perspective
}
La experiencia vivida de mujeres en la conyugalidad contemporánea: una perspectiva fenomenológico-existencial

\begin{abstract}
Resumo: Este artigo é resultado de uma pesquisa de mestrado que teve como objetivo compreender como as mulheres experienciam os atuais papéis que assumem nas relações conjugais contemporâneas e no exercício da maternidade, e quais os sentidos que atribuem a essas vivências. A partir da fenomenologia-existencial de Jean-Paul Sartre e das inestimáveis contribuições de Simone de Beauvoir sobre a situação da mulher, foi possível compreender como se desenvolve o projeto de ser das colaboradoras deste estudo, mulheres de classe média, trabalhadoras, vivendo em situação de relação conjugal, e com filhos, residentes em Fortaleza, Ceará. Para a coleta de dados foi utilizada a entrevista fenomenológica com a pergunta disparadora “como é ser mulher?”. Para a análise dos resultados foi utilizado o método Progressivo-Regressivo. Os resultados mostram que, mesmo com a instrução formal e a independência financeira das mulheres, os papéis femininos na conjugalidade têm sofrido poucas modificações com relação ao acúmulo de responsabilidades que recaem sobre elas. A crença em uma essência feminina perpassa a experiência vivida por essas mulheres na maternidade, na relação conjugal e no mercado de trabalho, indicando que ainda há diversos obstáculos à resolução dos problemas sociais que atravessam a história de vida dessas mulheres.
\end{abstract}

Palavras-chave: Mulher; Projeto de Ser; Conjugalidade Contemporânea; Fenomenologia Existencial; Sartre.

\begin{abstract}
This article is the result of a master's research that aimed to understand how women experience the roles in contemporary conjugality and in the exercise of motherhood, and what the senses they attribute to these experiences. From the existential-phenomenology of Jean-Paul Sartre and the invaluable contributions of Simone de Beauvoir about the situation of women, it was possible to understand how is developed the being project of the collaborators of this study, middle-class women, workers, living a relationship, and with children, residents in Fortaleza, Ceará. For data collect, the phenomenological interview was used with a triggering question "how is being a woman?". For the analysis of the results, the Progressive-Regressive method was used. The results show that, even with a formal instruction and a financial independence of women, their roles in conjugal relationships have undergone few modifications in relation to the increase of responsibilities that fall on them. The idea that there is a feminine essence permeates the experience lived by these women in motherhood, in the contemporary conjugality and in the job market, pointing out that there are still many obstacles to solve social problems through the life history of these women.
\end{abstract}

Keywords: Woman; Being Project; Contemporary Conjugality; Existential-Phenomenology; Sartre.

Resumen: Este artículo es el resultado de una investigación de maestría que tuvo como objetivo comprender cómo las mujeres experimentan los actuales papeles que asumen en las relaciones conyugales contemporáneas y en el ejercicio de la maternidad, y cuáles los sentidos que atribuyen a esas vivencias. A partir de la fenomenología-existencial de Jean-Paul Sartre y de las inestimables aportaciones de Simone de Beauvoir sobre la situación de la mujer, fue posible comprender cómo se desarrolla el proyecto de ser de las colaboradoras de este estudio, mujeres de clase media, trabajadoras, viviendo en situación de relación conyugal, y con hijos, residentes en Fortaleza, Ceará. Para la recolección de datos se utilizó la entrevista fenomenológica con la pregunta disparadora “cómo es ser mujer?”. Para el análisis de los resultados se utilizó el método Progresivo-Regresivo. Los resultados muestran que, incluso con la instrucción formal y la independencia financiera de las mujeres, los papeles femeninos en la conyugalidad han sufrido pocas modificaciones con respecto a la acumulación de responsabilidades que recaen sobre ellas. La creencia en una esencia femenina atraviesa la experiencia vivida por esas mujeres en la maternidad, en la relación conyugal y en el mercado de trabajo, indicando que todavía hay diversos obstáculos a la resolución de los problemas sociales que atraviesan la historia de vida de esas mujeres.

Palabras-clave: Mujer; Proyeto de Ser; Conyugalidad Contemporánea; Fenomenología Existencial; Sartre. 


\section{Introdução}

Este estudo apresenta os resultados de pesquisa de mestrado que teve como objetivo geral compreender os sentidos atribuídos pelas mulheres à experiência vivida na conjugalidade contemporânea, à luz da fenomenologia existencial de Jean-Paul Sartre (1943/2015). Dentre os objetivos específicos, buscou-se investigar: a) o projeto de ser mulher na conjugalidade contemporânea; b) os sentidos da experiência vivida dessas mulheres no exercício da maternidade. Toda a pesquisa foi realizada após aprovação do Comitê de Ética e mediante a assinatura do Termo de Consentimento Livre e Esclarecido (TCLE) por parte das colaboradoras do estudo.

A presente investigação visa contribuir, a partir de uma perspectiva fenomenológico-existencial, para o campo dos estudos de gênero. Segundo Connell e Pearse (2015), as pesquisas sobre as questões de gênero partiram de movimentos feministas, que têm como objetivo prioritário a equidade entre homens e mulheres, pois a maior parte das sociedades nas quais predomina a concepção binária dos gêneros outorga privilégios aos homens e coloca as mulheres em situação de desvantagem.

A situação das mulheres na contemporaneidade é uma construção social e histórica. Muitas das práticas relacionadas às mulheres na conjugalidade e na sociedade podem ser compreendidas a partir do contexto histórico do século XVIII, quando os administradores franceses começaram a introduzir práticas de controle e administração da vida sexual da população. Dessas práticas, originaram-se as posteriores formas de controle sobre os corpos das mulheres, sob a justificativa de se administrar os índices de natalidade (Foucault, 1999).

No século XIX, houve importante reformulação do discurso médico sobre o ato sexual, diferenciando a medicina do sexo da medicina do corpo, o que desencadeou uma descontrolada ênfase no discurso sobre a sexualidade na classe burguesa, ligada a uma forma poderosa do saber. Nesse momento o sexo foi definitivamente diferenciado da sexualidade (Foucault, 1999).

O que é possível verificar na atualidade é que as discussões sobre gênero ultrapassam a compreensão dos termos "homem" e "mulher" ligada aos fatores biológicos que os originam. Foi visando analisar e combater os argumentos naturalistas do determinismo biológico que em 1970 foi enfatizada a relevância da distinção entre sexo e gênero (Moore, 1997).

Compreender esse breve histórico e essa diferenciação entre sexo e sexualidade é importante para se compreender também os discursos que deram origem às crenças e práticas relativas às mulheres (suas subjetividades, seus corpos, seus direitos, etc.) que vigoram atualmente e que são discutidas neste estudo, o que favorece o entendimento das implicações desses discursos na experiência vivida pelas mulhe- res na conjugalidade contemporânea. A importância dessa questão se apresenta à medida que se compreende que até mesmo as identidades são aprendidas socialmente dentro de um campo de possibilidades da realidade vivida (Benevides, 2018).

É fato que esse vir a ser se dá no campo das possibilidades permitidas pela facticidade da realidade na qual a mulher, de fato, existe, mas Beauvoir (1949/2016a), defende que se há algo na mulher que já se apresenta como especificado sexualmente, isso acontece por meio da intervenção dos discursos de outras pessoas na vida da criança. No sentido fenomenológico, pode-se dizer que para compreender o projeto de ser mulher é preciso que se considerem as escolhas dessa mulher e o grau de autonomia nelas envolvido a partir da sua inserção no contexto de relações sociais concretas (Biroli, 2013).

A primeira consideração a se fazer para a compreensão desses discursos sobre a mulher diz respeito às dicotomias que tomam as mulheres como opostas aos homens, e é preciso compreender como se configurou tal discurso. Esse dualismo entre masculino e feminino é baseado na verdade do corpo, numa supremacia da força física masculina, que se estende a todos os níveis da vida por intermédio de uma ideologia que se apossa dessa dicotomia primeira (Badinter, 1986), que considera as mulheres frágeis e inferiores aos homens.

A diferenciação entre masculino e feminino foi inicialmente definida pela dicotomia força/fragilidade, posteriormente foi definida pela oposição entre corpo e razão, de tal modo que a mulher foi tida como oposição binária ao homem a partir de uma visão masculina do mundo (Biroli, 2013).

Aos poucos e aparentemente sem oferecer grandes resistências, as mulheres foram sendo relegadas a ocupar um lugar secundário na sociedade (Beauvoir, 1949/2016a). Mesmo em sociedades nas quais era possível entrever certa igualdade entre os sexos, a mulher foi representada, num discurso maniqueísta, como o mal, o que foi extremamente reforçado pelos discursos religiosos que tomaram como base o mito do Éden para a explicação do início da humanidade (Badinter, 1986).

Nos discursos mais antigos, a razão para que se tenha descrito a mulher dessa forma repousa numa suposta natureza feminina de "sensualidade desenfreada, impossível de ser satisfeita por um só homem" (Badinter, 1986, p. 135). A partir disso, é possível constatar como os discursos biologicistas e religiosos tentaram estabelecer uma natureza feminina reduzindo as mulheres às facticidades de seus corpos.

O corpo e a sexualidade das mulheres causavam grande temor aos médicos. Nessa época a loucura era uma grande preocupação da medicina e o temperamento nervoso era frequentemente considerado como típico das mulheres (Engel, 2009).

Na transição para o século XX as mulheres já 
eram autorizadas a trabalhar, mas com profissões ligadas ao feminino. Pela exigência de um contingente maior de força trabalhadora, as mulheres foram enviadas às fábricas, porém destinavam-se a elas as atividades menos qualificadas na hierarquia laboral (Matos \& Borelli, 2013).

A questão do lugar da mulher na família e na sociedade foi enfatizada pela crítica marxista emergente, porém esta falhou, em parte, ao considerar a luta de classes como o centro das opressões sociais, não levando em consideração as situações de opressão baseadas nos discursos sobre as diferenças sexuais. Miguel (2017) corrobora essa ideia quando afirma que o fato de o marxismo ter colocado a luta entre classes como fonte de todas as formas de opressão social fez com que as demandas feministas fossem diminuídas em sua relevância.

De maneira geral, os papéis masculino e feminino na sociedade vêm apresentando mudanças. Se hoje as mulheres ainda sofrem com a dupla jornada, a responsabilidade sobre a realização das tarefas domésticas e os cuidados com os filhos também tem se estendido, embora bem menos obrigatoriamente, para os homens (Unbehaum, 2001).

As mudanças nas configurações familiares e nas relações de trabalho já são uma realidade na contemporaneidade, porém essas mudanças não ocorrem sem conflitos entre as dimensões pessoais, do trabalho e da família e são ressaltadas pelo estudo de Madalozzo e Blofield (2017), que enfatiza a participação dos pais na criação dos filhos nas famílias de baixa renda em São Paulo.

De maneira geral, a conjugalidade é uma experiência que permite, acima de tudo, a união de interesses. A união conjugal surge para os mais pobres como meio de organizar o trabalho agrário (Giddens, 1992). Para os mais ricos, consiste em aliança necessária à manutenção, ampliação e tentativa de eternização da propriedade privada (Beauvoir, 1949/2016a).

Mesmo considerando todas as mudanças ocorridas na vida das mulheres até o presente momento, é preciso fazer uma relação entre os fatores econômicos, históricos e culturais que estão implicados nessas transformações. Ramos (2015) contribui com essa ideia ao afirmar que os discursos naturalizantes que ainda existem na contemporaneidade foram criados por uma ordem econômica dominante com o objetivo de transmitir uma ideia de imutabilidade dos institutos, para que assim houvesse um maior controle das tendências a criticar as normas existentes. Por isso, é preciso demonstrar como a organização familiar e a moral sexual devem continuar sofrendo modificações, sob pena de perpetuação das desigualdades entre homens e mulheres.

Pensando a partir de uma postura fenomenológica sartriana, é impossível aceitar discursos moralizantes e naturalizantes sobre a mulher. O existencialismo ateu, no qual se situa o pensamento de Sartre
(1943/2015), elimina a noção de um Deus criador e enfatiza que, se Deus não existe, "há pelo menos um ser cuja existência precede a essência, um ser que existe antes de poder ser definido por qualquer conceito" (Sartre, 1946/2016, p. 19), e esse é o ser humano.

A contribuição do pensamento sartriano para o presente estudo reside no entendimento de que, reconhecendo que a existência precede a essência, é impossível definir o que é ser mulher. Para Sartre (1946/2016), não é possível conceber uma definição para o ser humano e, se esse ser não é passível de ser definido, então ele é, essencialmente, nada.

É a partir da condição nadificante do ser da consciência, que se pode compreender o caráter ao mesmo tempo universal e singular da experiência humana. É diante do ser feminino, cuja condição ontológica é nada, que o mundo se apresenta e, assim, a percepção individual de cada mulher "se articula sobre o fundo ontológico da presença ao mundo, e o mundo se desvela concretamente como fundo de cada percepção singular” (Sartre, 1943/2015, p. 243).

Não havendo nenhuma natureza ou Deus que possa dizer como se deve ser mulher, cada pessoa é lançada no mundo numa realidade específica, sem que possa escolher as condições de seu nascimento, estando assim desamparada de qualquer possibilidade determinante ou de um destino a ela designado. Assim, a mulher depara, impelida pela sua condição de ser liberdade no mundo, com a responsabilidade de escolher como deve se fazer/tornar mulher (Benevides, 2018).

Considerando que a realidade da mulher não pode fazer aparecer o ser mulher como uma totalidade organizada no mundo, a menos que ela o transcenda, a mulher encontra-se sempre separada do que é pela espessura das coisas que não é (Sartre, 1943/2015), e essa falta de definição revela-se sempre num movimento de vir a ser, num projeto de ser mulher, que refuta toda possibilidade de um determinismo natural. O projeto de ser é um permanente movimento de devir e constitui questão central na filosofia de Sartre (1943/2015) e de Beauvoir (1949/2016a, 1949/2016b).

\section{Método \\ Caracterização da pesquisa e o método Progressivo- -Regressivo}

Esta é uma pesquisa qualitativa de caráter fenomenológico constituída a partir da perspectiva e do método sartriano. A pesquisa fenomenológica não almeja estabelecer relações causais nem busca explicações, porém objetiva descrever diretamente a experiência tal como ela é (Triviños, 1987).

Melo (2014) afirma que, na pesquisa fenomenológica, o pesquisador se coloca diante dos fenômenos na forma de dados factíveis, acrescentando que 
Sartre a define como modalidade de investigação que se dedica aos fenômenos que não podem ser puramente sentidos, pois não há nada no mundo que possa ser vivido sem objetivação.

O presente estudo também assume o caráter de pesquisa fenomenológica sartriana pela visão de sujeito adotada, ou seja, por considerar o ser humano, mais especificamente a mulher, em sua condição ontológica de liberdade situada na realidade da qual faz parte. É preciso que se leve em consideração todos os caracteres da situação, como os arredores, o lugar, o passado e todas as relações que esse ser faz com o mundo enquanto é para-si (Sartre, 1943/2015), compreendendo também que o ser humano se faz pelo seu projeto, superando perpetuamente a condição que lhe foi dada (Sartre, 1946/2016).

Finalmente, esta pesquisa se compreende sartriana pela aplicação do método criado por Sartre (1946/2016), um método fenomenológico que serviu de meio para se chegar à compreensão do fenômeno em questão e para a análise dos dados coletados junto às participantes da pesquisa.

O método progressivo-regressivo que foi desenvolvido por Sartre (1978) consiste na investigação que busca a compreensão dos aspectos singulares e universais da experiência vivida (Melo, 2014). Esse método foi escolhido como o mais adequado a este estudo por possibilitar a compreensão da dimensão de liberdade ontológica dos sujeitos pesquisados, bem como da responsabilidade dos sujeitos perante sua condição de liberdade em situação. Dessa forma, os sujeitos em questão são considerados no sentido humanista do termo utilizado por Sartre (1946/2016), que formula seu método a partir da concepção de um ser humano que só se faz na ação.

A contribuição sartriana para esta investigação vai muito além do método, mas possibilita a discussão e contextualização das condições históricas das mulheres, questão já tratada por Beauvoir (1949/2016a, 1949/2016b), para que se possa compreender o fenômeno do papel feminino na conjugalidade contemporânea. Segundo Schneider (2008), para que isso aconteça, é preciso ir além daquilo que a pessoa fala, de sua linguagem ou reflexão acerca de si mesma, é preciso descrever sua experiência vivida, seu contexto, suas práxis cotidianas.

O método progressivo-regressivo compreende que existe um movimento de vai e vem que é realizado pelo próprio sujeito durante sua narrativa, quando discorre sobre os sentidos que elabora a partir de sua própria existência. É um ir e vir que se revela no ato reflexivo do sujeito a partir do seu passado, em função da facticidade do seu presente e da possibilidade de vir a ser projetado no futuro. Com relação a essa temporalidade à qual está submetido o ser da consciência, o passado é parte constitutiva da situação, pois é impossível a existência ser no mundo sem que exista um passado (Castro \& Ehrlich, 2016).

A compreensão da temporalidade, principal- mente no seu aspecto psíquico, foi fundamental para a aplicação do método sartriano. É impossível ao ser humano existir no puro aqui e agora, haja vista que existir é ser ao mesmo tempo passado, presente e futuro, em um movimento de perpétua metamorfose. Dessa forma, a temporalidade psíquica apresenta-se ao sujeito por intermédio do ato reflexivo, que se constitui a partir da temporalidade originária (Castro \& Ehrlich, 2016).

Sendo assim, o método sartriano serviu aos objetivos deste estudo na medida em que contribuiu para a compreensão da experiência vivida das colaboradoras, considerando que essa experiência nunca é constituída por fatos isolados. É preciso ilustrar o entrelaçamento dos fatos em uma perspectiva dialética e histórica para que seja possível compreender a vida de uma pessoa ou de uma coletividade, considerando a especificidade da existência humana em sua concretude, em uma realidade que é objetiva, material, social e sociológica (Schneider, 2008).

\section{As Colaboradoras da Pesquisa}

As mulheres participantes desta pesquisa foram denominadas de colaboradoras. Andrade e Holanda (2010) citam Amatuzzi ao afirmarem que os sujeitos participantes da pesquisa são chamados de colaboradores por compreender que os sujeitos não são simples fornecedores de informações. Ele parte do pressuposto metodológico de que é o colaborador quem realmente sabe de sua experiência e pode descrevê-la melhor, realizando com o pesquisador uma troca, na qual ambos se transformam (Andrade \& Holanda, 2010).

Essa concepção acerca dos colaboradores da pesquisa é corroborada por Sartre (1943/2015) quando revela que eles dão informações objetivas sobre a sua própria experiência. Ao fim da experiência de pesquisa, o resultado obtido só pode ser "uma relação estabelecida entre duas séries de objetos" (p. 395), aqueles que se revelam durante a experiência e aqueles que, ao mesmo tempo, revelam-se ao pesquisador, confirmando a afirmativa amatuzziana de um sujeito que colabora para a experiência transformadora da pesquisa.

Nesse sentido, foram estabelecidos os critérios de inclusão e exclusão das colaboradoras. Nesta pesquisa, devido à impossibilidade de se abarcar a pluralidade das formas de conjugalidade, optou-se por investigar a experiência vivida de mulheres que convivessem em regime conjugal com cônjuges do sexo masculino, considerando que a relação heterossexual é apenas uma das inúmeras formas de relação conjugal e não estebelece de nenhuma maneira uma determinação sobre a forma como as mulheres experienciam a conjugalidade, considerando que a experiência vivida dessas colaboradoras é uma experiência singular, não sendo possível estabelecer nenhum tipo de julgamento de suas experiências 
como tábua de correlação com outras experiências (Sartre, 1943/2015).

Também como critério de seleção, optou-se por trabalhar com mulheres que estavam em relação conjugal há pelo menos 1 (um) ano, para que fosse possível avaliar minimamente a experiência vivida na relação conjugal. Outro critério utilizado para a seleção das colaboradoras foi a existência de filhos na relação, provenientes da própria relação conjugal ou de relações anteriores, mas que convivessem diariamente com o casal. Este critério foi estabelecido a partir de informações levantadas também na pesquisa bibliográfica (Badinter, 1986; Beauvoir, 1949, 2016b), que trata da situação da mulher com filhos como uma situação que pode, de alguma forma, interferir na experiência vivida pela mulher na conjugalidade. A conjugalidade em si não impõe a oficialidade da união, portanto, esta pesquisa incluiu as mulheres que se consideraram e se afirmaram, elas próprias, nessa situação.

Também como critério de inclusão, optou-se por trabalhar com mulheres da classe média, sendo esse critério correspondente aos arredores tratados por Sartre (1943/2015). A condição social dos casais com seus filhos coloca diante das famílias em ques- tão uma determinada condição financeira, representada pelos seus arredores, o complexo de utensílios com os quais estão implicados e que manipulam ou usam (Castro \& Ehrlich, 2016) e que acabam fornecendo subsídios para o fazer dessas mulheres no mundo em direção aos seus projetos. A condição econômica decorrente da classe social coloca diante dos sujeitos a facticidade de seus arredores, e é compreensível que famílias classificadas como "classe alta" e "classe baixa" apresentem particularidades que não interessam a este estudo.

Para a seleção das colaboradoras a partir dos critérios de renda, utilizou-se a "Síntese de indicadores sociais" do Instituto Brasileiro de Geografia e Estatística (IBGE) referente ao ano de 2014, que classifica classe média as famílias que têm renda aproximada entre 3 (três) e 9 (nove) salários mínimos.

Segundo os dados do IBGE (2014), a configuração das famílias brasileiras está profundamente relacionada à renda familiar per capita, e as mulheres que vivem em relação conjugal, e com filhos representam 14,5\% do total de famílias com renda superior a 2 (dois) salários mínimos, o que indica a Tabela 1:

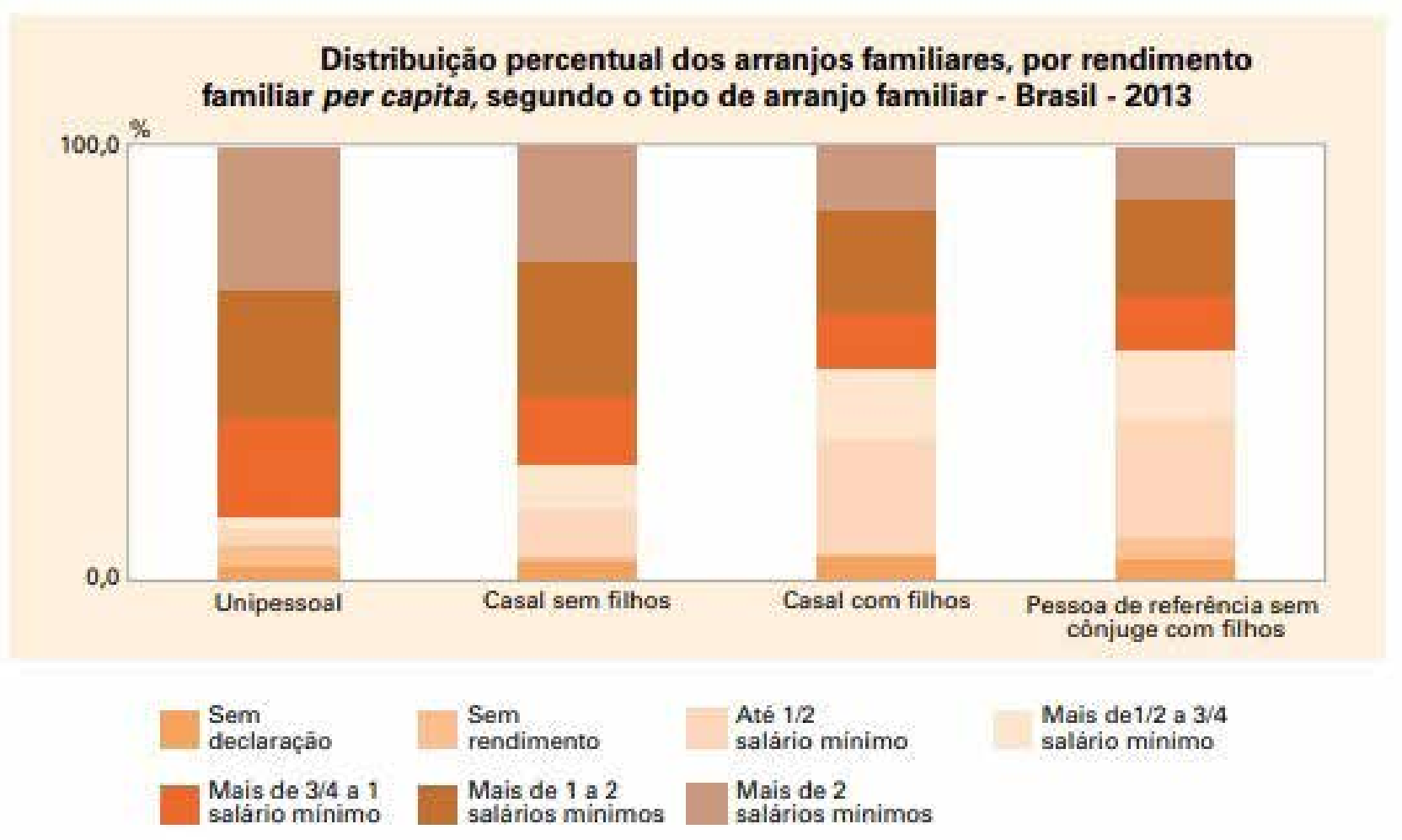

Fonte: IBGE, Pesquisa Nacional por Amostra de Domicilios 2013.

Tabela 1

Distribuição Percentual dos Arranjos Familiares, por Rendimento Familiar Per Capita, Segundo o Tipo de Arranjo Familiar - Brasil - 2013. 
Uma informação importante a ser considerada com relação à atuação da mulher na conjugalidade e na família, é que o aumento da participação das mulheres no mercado de trabalho alterou consideravelmente a configuração dos arranjos familiares brasileiros nos últimos anos (IBGE, 2014). Dessa forma, também foi um critério de inclusão das colaboradoras que elas exercessem alguma atividade remunerada, possuindo alguma renda que pudesse justificar sua adequação aos critérios de classe exigidos para a participação nesta investigação.

Considerando ainda o critério de participação das mulheres no mercado de trabalho, os dados do
IBGE (2014) refletem uma realidade discrepante com relação aos problemas estruturais das famílias brasileiras.

A razão entre os rendimentos de todos os trabalhos do cônjuge e da pessoa de referência revelam desigualdades entre homens e mulheres, mesmo estando essas últimas em posição de destaque no âmbito familiar. Em 2013, em 76,3\% dos arranjos de casais nos quais a mulher era a pessoa de referência, os cônjuges tinham rendimento igual ou superior a elas. Em 2004 essa proporção era de 70,6\%. Essa disparidade é apresentada pela Tabela 2:

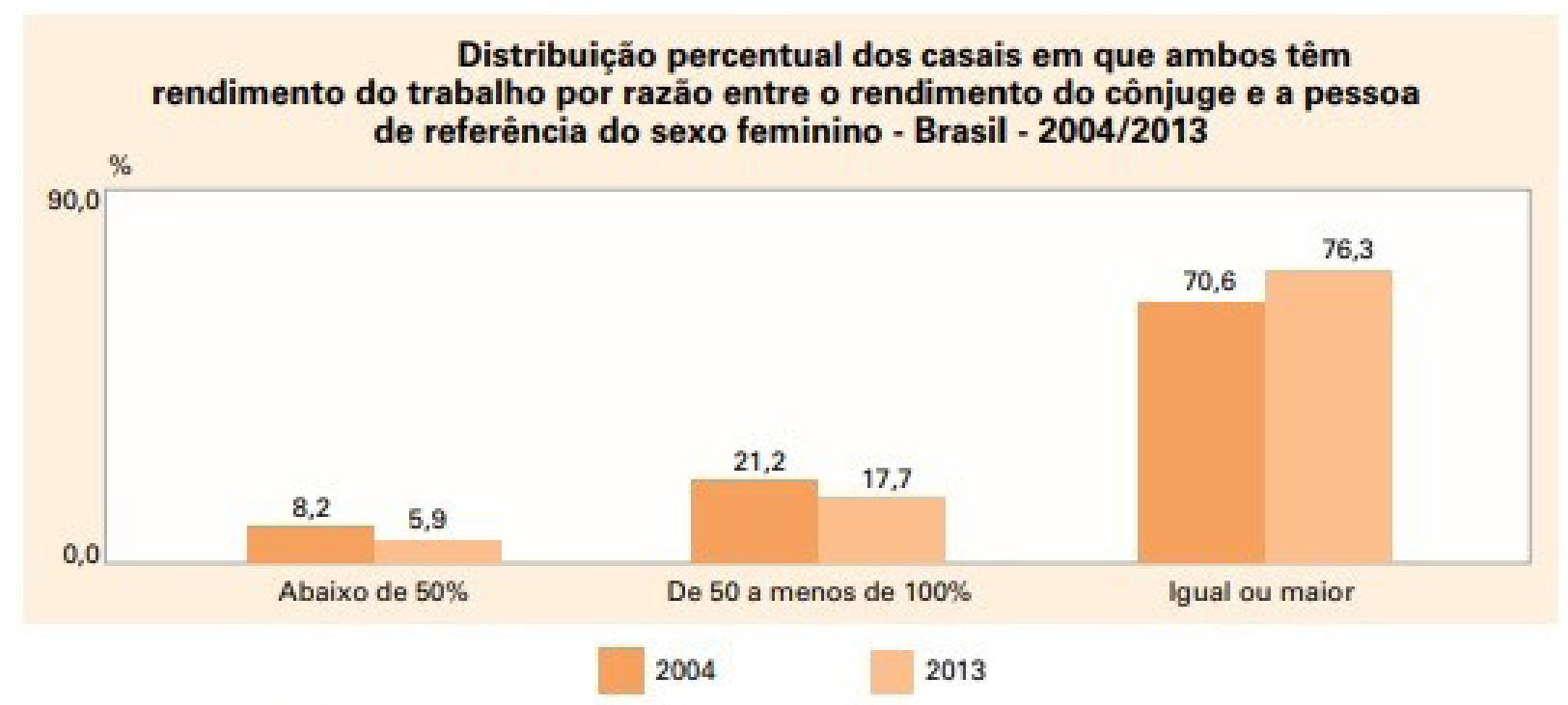

Fonte: IBGE, Pesquisa Nacional por Amostra de Domicilios 2004/2013.

Nota: Proporçóes calculadas com a soma dos rendimentos de todos os trabalhos.

Tabela 2

Distribuição Percentual dos Casais em que Ambos Têm Rendimento do Trabalho por Razão Entre o Rendimento do Cônjuge e a Pessoa de Referência do Sexo Feminino - Brasil - 2004/2013.

Os dados estatísticos apontaram informações relevantes para a escolha dos critérios de inclusão e exclusão das colaboradoras deste estudo e para a posterior análise da situação delas. Assim, a pesquisa foi realizada com um número de 10 (dez) mulheres, considerado um número viável para a análise dos dados fornecidos por elas.

As colaboradoras residiam em Fortaleza e provinham do estado do Ceará. Esse foi um critério estabelecido devido ao aspecto cultural do lugar, que pode influenciar ou servir de referência para as falas, valores e crenças das mulheres selecionadas. Para Sartre (1943/2015), o lugar se define pela ordem espacial e a natureza singular das coisas que se revelam às pessoas que ali habitam, é o país com seu solo, seu clima, suas riquezas, sem os quais o mundo não iria se manifestar ao sujeito de forma alguma.

Para fins de exclusão, não interessaram a esta pesquisa as mulheres solteiras, divorciadas e sem filhos, ou cujos filhos não convivessem com o casal, pois essa não era a situação da qual partiu este estudo, considerando que o fato de terem um cônjuge e um ou mais filhos alterava as condições sociais e econômicas da mulher. Também não foram aceitos cônjuges que vivessem em domicílios diferentes. Foi ainda um critério de exclusão a nacionalidade estrangeira de qualquer um dos cônjuges, devido aos fatores culturais que pudessem vir a interferir na dinâmica dos casais.

Todos esses caracterizaram-se como critérios de inclusão e exclusão das colaboradoras, pois a situação da qual fala Sartre (1943/2015) se constitui a partir das dimensões que o filósofo chama de meu lugar, meu passado, meu próximo, meus arredores e minha morte, considerados na etapa de análise e discussão dos dados. Portanto, a situação da qual partiu este estudo foi a de mulheres heterossexuais, cearenses, que residissem na cidade de Fortaleza, tivessem 18 (dezoito) anos de idade ou mais, estivessem em uma relação conjugal, que pertencessem 
à classe média da população, tivessem filhos e vivessem conjugalmente sob o mesmo teto com marido e filho(s) há pelo menos 1 (um) ano.

Em conclusão, as colaboradoras desta pesquisa estavam numa faixa etária entre 26 (vinte e seis) e 48 (quarenta e oito) anos, com tempo de relacionamento conjugal entre 1 (um) ano e 7 (sete) meses e 28 (vinte e oito) anos. Elas tinham de 1 (um) a 2 (dois) filhos com idades entre 6 (seis) meses e 25 (vinte e cinco) anos.

\section{O Instrumento da Pesquisa}

Esta pesquisa utilizou a entrevista fenomenológica como ponto de partida para a obtenção das informações necessárias junto às colaboradoras, considerando que esse instrumento poderia ser um método eficaz para a compreensão da experiência vivida por elas. Para Ranieri e Barreira (2010), a entrevista fenomenológica é um meio que permite a narração das experiências vividas pelas pessoas. É o instrumento que condiz mais adequadamente ao objetivo e método deste estudo devido à sua especificidade de não estabelecer $a$ prioris sobre a experiência vivida, propiciando uma melhor compreensão dos fatos estudados.

A pergunta norteadora desta pesquisa foi “como é ser mulher?”. O intuito inicial foi provocar a fala das colaboradoras sobre sua situação atual, trazendo já à luz deste estudo a dimensão da experiência vivida por elas, incluindo seu passado. Sartre (1943/2015) afirma que o passado é o que é, é um em-si e, como tal, não pode ser modificado. Nesse sentido, o passado não é determinante das ações das pessoas, mas é a partir dele que são tomadas todas as decisões no presente. Nesse sentido, os resultados aqui apresentados são fruto de uma análise com ênfase sobre o aspecto regressivo do método sartriano, sendo o passado um importante dado para a compreensão da experiência vivida pelas colaboradoras.

Outras perguntas, também não diretivas, foram utilizadas para retomar as falas das colaboradoras quando elas se distanciavam do tema inicial ou davam informações superficiais, que não possibilitavam a compreensão da complexidade de suas experiências. Eram perguntas pertinentes aos conteúdos explicitados por elas, de forma que eram feitas perguntas não planejadas inicialmente. A possibilidade de introduzir novas perguntas também caracteriza o instrumento desta pesquisa como uma entrevista semiestruturada, que dá um maior valor à presença do pesquisador, favorecendo a liberdade e a espontaneidade das colaboradoras, o que é necessário à investigação (Triviños, 1987).

\section{O Procedimento de Coleta e Análise dos Dados}

O primeiro procedimento realizado nesta pesquisa foi a convocação e seleção das colaboradoras.
A convocação ocorreu mediante a indicação de mulheres (dentro do perfil solicitado) por pessoas da rede de contatos profissionais da pesquisadora.

O contato inicial com as mulheres selecionadas foi realizado de forma a esclarecer o objetivo da pesquisa, verificar a correspondência das possíveis colaboradoras aos critérios exigidos para a participação e entregar o Termo de Consentimento Livre e Esclarecido (TCLE), que foi assinado por elas para autorização do uso e publicação parcial ou integral de suas falas sobre suas experiências vividas, resguardando devidamente suas identidades por meio da utilização de pseudônimos, as de seus cônjuges, familiares ou outras pessoas e instituições que pudessem vir a ser citadas durante as entrevistas.

A segunda etapa desta pesquisa foi a entrevista, realizada individualmente com cada pessoa, garantindo-se o sigilo necessário. Todas as entrevistas foram realizadas mediante a seguinte pergunta disparadora: “como é ser mulher?”. As entrevistas foram gravadas em áudio pela pesquisadora, mediante consentimento das colaboradoras, e tiveram duração média de 45 minutos.

A etapa seguinte consistiu na transcrição das falas das colaboradoras. Para a transcrição foi utilizada a versão livre do software InqScribe ${ }^{\circledR}$ (versão 2.2.3.258), que permite que o pesquisador reproduza e transcreva os áudios das entrevistas numa mesma tela, favorecendo a retomada de partes específicas dos áudios e viabilizando uma transcrição ágil dos dados coletados.

A última etapa deste estudo foi a análise das falas das colaboradoras a partir do método biográfico sartriano, objetivando compreender os sentidos construídos pelas mulheres sobre a experiência vivida na relação conjugal. As falas foram recortadas, classificadas e analisadas para que pudessem fornecer dados que fossem ao encontro dos objetivos específicos deste estudo.

\section{Aspectos Éticos da Pesquisa}

Toda a pesquisa foi realizada obedecendo às exigências da Resolução $n^{\circ} 466$, de 12 de dezembro de 2012, do Conselho Nacional de Saúde, que trata da pesquisa envolvendo seres humanos que, dentre outras coisas, estabelece que o pesquisador deve garantir a assistência imediata e gratuita para os participantes do estudo. O parecer do Comitê de Ética foi favorável à pesquisa.

\section{Resultados \\ Como é Ser Mulher? Trabalho, Conjugalidade e Ma- ternidade}

Para as colaboradoras deste estudo, ser mulher parece ser uma experiência ambígua, ao mesmo tempo árdua e gratificante. Segundo a colaboradora Pau- 
la, ser mulher é difícil, pois a mulher exerce diversos papéis na sociedade, "vários, não só cuidar da família, mas também tem que trabalhar".

O trabalho apareceu como uma das maiores preocupações das mulheres entrevistadas. Fazendo-se uma análise regressiva do discurso da colaboradora Cláudia, ela recordou de sua infância e fez referência à mãe quando começou a falar de trabalho. Paula também se referiu à mãe e à infância quando lembrou do seu passado e ao falar de trabalho. Fazendo-se o movimento regressivo, ambas se recordaram da infância e de como viam suas mães. Elas revelaram diferenças entre a sua situação no presente e a situação do passado de suas mães, que nem sempre tinham a necessidade de conciliar o trabalho doméstico com o trabalho profissional.

Esse trabalho profissional ao qual as colaboradoras se referem é umas das dimensões da vida da mulher que exige dela uma conciliação árdua entre família e carreira. Para Adriana, ser mulher casada, que trabalha e que tem filhos, é tarefa difícil, porém gratificante. Ao descrever sua rotina, ela elucida bem isso: "Ontem mesmo, 11 horas da noite, eu estava fazendo almoço para o outro dia. Tive que acordar hoje 6 horas da manhã sem estar cansada, tem que estar disposta.".

Essa exigência também apareceu na fala da colaboradora Paula, para quem há cobrança pessoal e social para que realize todas as atividades relacionadas ao trabalho doméstico, sendo-lhe ainda imposto que cuide do aspecto profissional, da família e da própria aparência.

A experiência vivida pelas colaboradoras demonstra que a situação atual dessas mulheres de classe média, com filhos e que vivem em relação conjugal com cônjuges do sexo masculino, é de acúmulo de atividades e de tentativa de conciliação entre as inúmeras responsabilidades que assumem após o casamento e a maternidade. Boa parte das colaboradoras relatou que a vida mudou muito após a chegada dos filhos e que suas responsabilidades com o lar aumentaram. Elas também se referiram ao passado de suas ancestrais para fazer uma analogia com a situação da mulher casada e com filhos na contemporaneidade, partindo de suas experiências pessoais e familiares.

Essa noção de acúmulo de responsabilidades está presente na fala de Mayara quando afirma que ser mulher é assumir mais atribuições do que acha que deveria. Para ela, é muito mais difícil ser mulher do que ser homem, porquanto o mundo parece ter sido feito para os homens. Em seu entendimento, os homens atualmente participam da criação dos filhos, mas as mulheres ainda ficam com a maior responsabilidade:

Eu acho que o mundo, pro homem, ainda é como antigamente. Homem trabalha, volta pra casa... E hoje em dia está mudando alguma coi- sa, porque eles ainda ajudam com as crianças mais do que antigamente. Com a mulher não, a mulher continua com os mesmos trabalhos de antigamente, mas mais. Mais ainda porque a gente, além da casa... o homem não dá um terceiro turno como a gente dá. É isso que eu quero dizer. A mulher trabalha em casa, trabalha com os filhos e trabalha fora. O homem trabalha fora e ajuda com os filhos, o que não deveria ser. (Mayara, 2018)

A chegada dos filhos apareceu como um dado da realidade das mulheres que tende a modificar abruptamente a existência da mulher. Bruna, mãe de dois filhos, falou do seu passado e de como se sente atualmente com relação ao papel de mãe, incluindo a forma como é vista socialmente: "Eu já fui mãe solteira, meu primeiro filho não é do meu esposo, é de um outro relacionamento, então ser mãe solteira é muito difícil, são cobranças de outra ordem."

A experiência vivida por Bruna produziu dados importantes à compreensão da situação da mulher casada com filhos e da mulher solteira com filhos. Em sua visão, a mulher precisa socialmente da presença do homem para dar legitimidade à sua experiência como mulher e mãe, o que ela considerou algo difícil de ser vivido, como se evidencia na transcrição de seu relato a seguir:

Eu vejo que só pelo fato de há dois anos eu ter um companheiro, que divide comigo essas responsabilidades, socialmente, a visão das pessoas ao meu respeito, embora eu não tenha casado oficialmente, mudou. Até de convidarem o meu filho pra festas, aniversários de colegas. Isso mudou dentro de dois anos só porque eu tenho um companheiro. Então a mulher ainda precisa de um homem para legitimar a existência dela, entendeu? Meu filho era invisivel, muitas festas, muitos aniversários ele não era convidado enquanto eu era mãe solteira. Depois que eu passei a ter um companheiro, meu filho se tornou visível, socialmente aceito e eu socialmente aceita. A mulher ainda precisa de um homem para legitimar até a existência dela, entendeu? (Bruna, 2018)

Apesar de a conjugalidade mudar a forma como as mulheres são vistas socialmente (Beauvoir, 1949/2016b), a maior mudança na vida delas ocorre após a maternidade. A mudança que a maternidade provoca na vida das mulheres também inclui, além de novas responsabilidades, a restrição de algumas atividades que exerciam anteriormente.

Isso é o que elucida a fala de Lurdes, mãe de dois filhos. Em seu discurso, ela fez um movimento regressivo, relatando como sua vida se transformou após a maternidade. Lurdes também relatou a transformação da sua situação após a maternidade e a tentativa que fez, assim como as outras mulheres, de conciliar as atividades profissionais com o 
trabalho de cuidado com os filhos, e apontou para a possibilidade, apesar das dificuldades, de conseguir trabalhar fora de casa e a satisfação pessoal que o trabalho lhe proporciona:

Ao mesmo tempo que é doloroso, que a roupa aperta, eu adoro essa coisa de sair de casa, de ser eu, de não ser a mãe. Eu adoro isso, adoro ser o que eu sou, fazer o que eu sempre fiz. (Lurdes, 2018)

Mariana também afirmou que o trabalho produz uma espécie de alívio para a rotina:

Você fica muito focada no lance do filho e chega uma hora que você pira e a hora que entra o trabalho é a hora que tu tem uma... "espera, calma, eu tenho outra vida além disso aqui”. (Mariana, 2018)

Essa fala também elucida o sentimento de ambiguidade que boa parte das colaboradoras indicaram na experiência vivida como mães. Há na maternidade uma satisfação pessoal, assim como há o peso das responsabilidades. Sobre isso, Bruna falou que ser mãe "às vezes é odioso, você ama, é meio paradoxal”.

Beauvoir (1947/1970) declara que essa ambiguidade representa "dois aspectos da realidade que não se distinguem à primeira vista” (p. 110). A ambiguidade foi compreendida como experiências singulares de êxitos e fracassos pessoais dessas mulheres no desempenho dos papéis que assumiram no lar, na conjugalidade e no exercício da maternidade.

Elas revelaram que as mudanças que a conjugalidade e a maternidade trouxeram aos seus projetos não foram, na maior parte das vezes, escolhas conscientes. Não obstante, a escolha é feita mesmo que não se possa dimensionar as consequências que podem advir de cada ação. Segundo Beauvoir (1947/1970), cada ser humano tem que "decidir sobre si mesmo nas trevas" (p. 118).

Por intermédio de suas falas, as colaboradoras indicaram que o projeto de ser mulher não necessariamente incluía o projeto de ser mãe, nem mesmo o projeto de ser casada. A eleição da conjugalidade já depara desde o princípio com um paradoxo. Para se adentrar e vivenciar o fenômeno da conjugalidade, faz-se necessário o direcionamento do projeto de ser rumo ao projeto de um outro. A presença desse outro revela-se indispensável para que a vida conjugal obtenha êxito. Há consideráveis transformações no projeto de ser mulher quando a ele são agregados também o projeto de ser casada e o projeto de ser mãe. Algumas dessas transformações na vida das mulheres nem sempre são recebidas de forma agradável, e chegam a causar atritos entre os cônjuges e também entre os familiares que residem com o casal.

Isso é o que é indicado por Mariana que, após a maternidade, teve sérias mudanças na vida conjugal da colaboradora. Com as novas atribuições que chegaram com o nascimento do primeiro filho do casal, chegaram também novas necessidades, que fizeram com que os cônjuges tivessem que rever seus papéis e responsabilidades dentro da relação. O cônjuge de Mariana optou por abster-se das atividades domésticas. Essa foi uma escolha do cônjuge que influenciou diretamente no projeto de ser casada de Mariana, fazendo com que ela repensasse essa situação.

\section{A Situação da Mulher Casada: Tarefas Domésticas e Papéis de Gênero}

Com o nascimento dos filhos, as colaboradoras revelaram grandes mudanças em suas vidas. Ao dar início ao seu projeto de ser mãe, a mulher acaba assumindo também outros papéis e responsabilidades. Com a chegada dos filhos, as mulheres revelaram que suas obrigações com o lar aumentaram. Essas novas responsabilidades provocam nas mulheres sentimentos ambíguos, como a culpa e a sensação de recompensa. Esses sentimentos parecem ainda bastante permeados por valores culturalmente adquiridos sobre o papel social da mulher na família. Sobre isso Diana afirma: "a mulher ainda tem aquela crença de que é a mulher que tem que cuidar da casa e da família. Realmente, é o papel da mulher, porque ela é mais delicada e ela entende um pouco mais".

A fala de Diana pareceu evocar uma ideia de natureza feminina de delicadeza, capaz de dar conta de determinadas atividades que seriam então mais apropriadas às mulheres que aos homens, como cuidar da casa. Essa ideia de uma natureza feminina também apareceu na fala de Adriana: "Se eu pudesse nascer de novo, eu ia querer nascer mulher, porque eu acho que é uma essência, que é uma dádiva. Eu acho que ser mulher é uma dádiva, entendeu?”.

Essa ideia de uma natureza que define o que é ser mulher parece influenciar na forma como algumas das colaboradoras realizam seus projetos, como se houvesse alguma receita ou um conjunto de condutas, regras e atributos que se sobrepõem às suas vidas, conferindo legitimidade à existência delas como mulheres. Quanto a isso, Beauvoir (1949/2016b) explica que "a ideia de feminilidade se impõe de fora a toda mulher, precisamente porque se define artificialmente pelos costumes e pelas modas" (p. 506).

Isadora também revelou em sua fala uma ideia de natureza feminina. Quando indagada sobre como é ser mulher, ela iniciou falando sobre sua concepção do que é ser mulher: "ser mulher é ser feminina, se cuidar, pensar em você, é tentar sempre estar bonita, ser sempre a palavra mais calma da sua casa, amenizar as situações”.

Isadora apontou em sua fala características que considerou tipicamente femininas, que influenciam atualmente seu papel dentro do lar. Realizando um 
movimento regressivo, ela relatou ser filha única e disse também que foi criada com todas as regalias que os pais puderam lhe oferecer. A vida de Isadora mudou com o casamento e, principalmente, após a chegada do filho, ela se tornou a cuidadora do filho e a organizadora do lar: "vejo que eles têm um cuidado muito grande comigo de 'cadê a mamãe?', 'o que ela está fazendo?'. Só isso, porque na hora de lavar pano, lavar chão ou essas coisas, eles não têm não". Ela também afirmou sentir falta da privacidade que tinha antes de casar e ser mãe, das atividades sociais e do lazer vivenciado com as amigas:

Por exemplo, uma coisa que hoje eu sinto falta é de ir pro barzinho com as minhas amigas, tomar uma cerveja, conversar e ir embora na hora que eu quiser, me divertir sem me preocupar com o marido, sem me preocupar com filho, isso não acontece mais. Eu não consigo mais nem ir ao banheiro sozinha. (Isadora, 2018)

O tempo para o lazer é algo que as colaboradoras relataram como sendo uma necessidade da qual passam a sentir falta após o casamento e, principalmente, após o nascimento dos filhos. O mesmo não parece acontecer com alguns dos cônjuges das mulheres entrevistadas. Paula, por exemplo, relata que, apesar de trabalhar durante toda a semana fora de casa, no final de semana realiza atividades domésticas para que o esposo possa ter tempo para o lazer com os amigos. Isadora afirma que o esposo considera comum sair para beber e retornar às três horas da manhã, mas não permite que ela faça o mesmo. Segundo ela, o esposo afirma que existem diferenças entre homens e mulheres que influenciam no que cada um pode/deve ou não fazer.

Mariana também revelou conviver com essa ideia de que há obrigações específicas para homens e mulheres, baseados no que seria a natureza de cada um:

Se eu tiver um garrafão de cinco litros pra pegar aqui, que um homem acabou de entregar aqui, eu não acho que seja o meu papel pegar. Porque eu tenho útero, porque como eu tenho útero, isso pode me prejudicar, pegar esse tanto de peso pode me prejudicar. (Mariana, 2018)

Com relação às restrições experienciadas pelas colaboradoras, o tempo e o espaço para o lazer e cuidados pessoais parecem diminuir consideravelmente após o nascimento dos filhos, isso fica explícito na evocação de Mayara. Ela disse que o lazer do casal muda depois do nascimento dos filhos: "Você tende a ir para locais que tenham criança, que sejam interessantes para criança também".

Beauvoir (1949/2016b) já denuncia que essa mudança que ocorre na vida das mulheres não é algo novo, mas que a mulher, de forma geral, tende a recusar que as novas responsabilidades trazem con- sigo alguma renúncia ou limitação, “ela se esforçará por negar essa limitação” (p. 220).

A colaboradora Laura declarou ter renunciado a algumas horas de trabalho e, consequentemente, a uma parte de sua remuneração, para acompanhar a vida estudantil da filha e dar mais atenção a ela, porém não é só com relação aos aspectos materiais que a vida da mulher pode sofrer alterações. O corpo e a sexualidade das mulheres também se modificam após a maternidade. Essa é uma afirmação comum à boa parte das entrevistadas. Sobre isso, Bruna relata:

A sexualidade, pra mim, também muda, né? A visão de mim, do meu corpo, da aceitação do corpo que, querendo ou não, por mais que meu esposo diga que estou linda, você vê, você sente a mudança no seu corpo. (Bruna, 2018)

Quanto a negarem as limitações e renúncias impelidas pelas mudanças ocorridas após o casamento e a maternidade, as colaboradoras revelaram sofrerem pressão para negarem que apresentam limitações físicas e emocionais para lidar com certas situações. A fala de Mayara confirma isso, quando afirma que é orientada pela mãe a não dizer que está cansada do cuidado com os filhos:

Sim, mas é um estado físico, é cansaço, não quer dizer que eu estou falando dos meus filhos... é a verdade isso, sabe? A gente escuta muito mesmo, você não pode falar. Já escutei até da minha mãe (Mayara, 2018)

Aparentemente, existe uma tentativa individual das colaboradoras de esconder que há certos sentimentos e sensações desagradáveis relacionados à conjugalidade e, principalmente, ao exercício da maternidade. Esse esforço realizado pelas mulheres tem como consequência alguns sentimentos, como frustração e culpa. Isso é o que Paula manifestou ao falar que não conseguiu acompanhar as atividades estudantis do filho mais velho. Mariana também afirmou que as responsabilidades do papel materno são muitas e as culpas recaem sobre a mãe quando ocorre algo de errado.

Isso faz parte do que as colaboradoras afirmaram ser o esperado do papel materno, como defendeu Bruna:

Então assim, acaba que a criação dos filhos é delegada, as responsabilidades, maior parte das vezes, só para a mulher. Mesmo que ela tenha um companheiro participativo, que seja tão ativo quanto ela, mas a sociedade ainda espera que seja dela esse papel, e só dela. (Bruna, 2018)

Laura também lembrou do passado e falou claramente das mudanças em sua vida após o nasci- 
mento da filha e das responsabilidades que recaíram mais sobre ela, e muitas vezes não eram partilhadas com o cônjuge. Segundo os relatos das colaboradoras, parece haver, no exercício da maternidade e no cuidado com os filhos, uma espécie de gratificação pessoal por cada mínima etapa do desenvolvimento dos bebês e pela relação estabelecida com eles, como retribuição do amor que dedicaram aos filhos.

Lurdes afirma que encontrou satisfação no papel de mãe: "Agora eles estão na fase de dar o bracinho pra ficar no braço, isso é muito gostoso! Eu não me arrependo e me vejo totalmente transformada.".

Essa e outras afirmações demonstram como o cuidado com os filhos, somado às responsabilidades com as crianças e o lar, tornam a maternidade uma experiência vivida de forma bastante paradoxal. Os papéis paterno e materno parecem ser compreendidos de formas diferentes pelas colaboradoras, embora todas tenham concordado que pais e mães devem assumir as mesmas responsabilidades na criação dos filhos. Essas diferenças sobre as responsabilidades que recaem sobre cada um, homem e mulher, após o nascimento dos filhos, aparecem mais claramente na divisão das obrigações domésticas.

A divisão dessas atividades aparece de forma bastante heterogênea nas experiências vividas das colaboradoras. No caso da colaboradora Mariana, a divisão desigual das responsabilidades com o filho e com o lar gerou conflitos entre ela e o cônjuge, conflitos esses que puseram a relação conjugal em risco. Diana afirmou utilizar o tempo de descanso para realizar as tarefas domésticas, enquanto isso, o esposo brinca com o filho, para que ela consiga se dedicar melhor às atividades referentes ao lar.

Mais especificamente no cuidado com os filhos, os papéis dos pais e das mães, segundo as colaboradoras, também é bem diferente. Aparentemente, o papel dos pais, segundo o que afirmaram algumas dessas mulheres, restringe-se, em grande parte, aos cuidados mais básicos e às brincadeiras com as crianças. Os cuidados mais específicos como alimentação e administração de remédios estão mais delegados às mães.

Bruna e Lurdes relataram que há uma igualdade na divisão das atribuições domésticas, porém essa não é a realidade de Isadora e Paula, que são provedoras de seus lares. Apesar da independência financeira, o fator econômico não as aliviou das obrigações domésticas. Isso é o que fica evidenciado pela evocação de Isadora:

Eu sou casada com homem, o macho alfa (risos). Ele acha que ele manda em tudo, mas ele não manda em nada... a maior provedora do lar sou eu, né? E ao mesmo tempo que a maior provedora sou eu, eu pago a maioria das contas, eu que mando, mas o meu marido não sabe. Ao mesmo tempo eu tenho que ser sim submissa ao meu marido, por ele ser o pai da família e ele ter um temperamento muito forte, ele é do interior de Goiânia, Goiás, né? Ele foi criado com aquela mentalidade que o homem manda, a mulher obedece. (Isadora, 2018).

Quanto a isso, Isadora também fala sobre o status social referente à pessoa que provê o sustento do lar, afirmando que chega a colocar dinheiro na carteira do cônjuge para que ele possa pagar contas e, publicamente, transparecer ser o provedor ou detentor do maior salário. Sobre isso ela diz: "eu dou dinheiro, ele bota dinheiro na carteira dele pra não parecer que sou que eu estou lá pagando, né?”.

Já a colaboradora Adriana, apesar de exercer atividade remunerada, evidenciou, assim como Cláudia, certa dependência financeira com relação ao cônjuge. Ambas relataram satisfação com os papéis que assumiram na relação conjugal. Quanto a isso, Adriana evidenciou que os papéis dela e do cônjuge na divisão da renda, das tarefas do lar e no cuidado com o filho são bem definidos: "Então assim, em casa, basicamente, eu faço tudo, entendeu? Lavar louça, lavar roupa, cuidar da minha filha. Ele é, basicamente, o papel financeiro".

Adriana e Cláudia, apesar de exercerem atividades remuneradas, evidenciaram dependência financeira com relação ao cônjuge. Cláudia relatou não ter sofrido sobrecarga de responsabilidades, pois a condição financeira do cônjuge possibilitou-lhe contar com o apoio remunerado de outras mulheres, que a ajudavam nas tarefas domésticas e nos cuidados com os filhos. Essa ajuda consiste no que algumas colaboradoras chamaram de "rede de apoio", quando outras mulheres, principalmente familiares, ajudam com as atividades do lar para que elas possam exercer suas atividades profissionais e terem alguns momentos de lazer.

Algumas questões como o feminismo e o empoderamento feminino, além da rivalidade entre mulheres, foram citados pelas colaboradoras, porém de forma bastante superficial, indicando que essas discussões aparecem para elas como algo distante de suas experiências vividas. Isso é apresentado na fala de Mariana sobre o discurso feminista e a discriminação entre mulheres, quando diz:

É o momento em que nós, categoria enquanto mulheres mesmo, categoria de mulher, deveríamos nos unir para que isso não acontecesse conosco, né? Pra que nós ficássemos cada vez mais fortes, como aconteceu na época da revolução feminista do sutiã lá. Então quero dizer, todo mundo queimou um monte de sutiã, mas foi porque um monte de mulher se juntou. Se um monte de mulher não se juntar agora, vou te falar, não sou feminista não, viu? Eu acho que cada um tem o seu papel dentro da sociedade e nós jamais poderemos nos igualar aos homens e vice-versa porque cada um realmente tem o 
seu papel, mas há coisas em que realmente nós somos iguais (Mariana, 2018).

Um dado semelhante sobre a compreensão da luta feminista aparece na fala de Diana. Ela afirma: "eu acho que ser mulher não é fácil realmente, a gente tá conquistando aí a cada dia, já que se toca tanto no assunto de empoderamento feminino, a gente tá crescendo aí no meio desse monte de marmanjo".

As evocações das colaboradoras do estudo evidenciam o quanto questões sociais essas questões permeiam suas experiências vividas.

\section{Considerações Finais}

Um dado relevante encontrado nesta investigação foi o modo como as práxis dessas mulheres contribuem para a transformação ou perpetuação de suas situações. Essas mulheres lidam com problemas e obstáculos diários com atitudes que transitam entre a indignação e a conformação, chegando, grande parte das vezes, a reproduzir os discursos que reforçam sua situação desprivilegiada com relação aos cônjuges, que parecem gozar de mais liberdade, autonomia e tempo para o lazer, além de serem menos obrigados com as atividades domésticas e de cuidados com os filhos.

O que as estatísticas (IBGE, 2014) mostram é que as mulheres que são chefes de família, de maneira geral, ainda sofrem com a desigualdade de gênero no mercado de trabalho, principalmente no que se refere à remuneração inferior que recebem em relação à remuneração dos homens, e com a sobrecarga decorrente da dupla jornada de trabalho.

No universo de colaboradoras deste estudo, apenas uma delas declara-se ciente da sua situação singular diante da condição histórica e socioeconômica da coletividade que integra, porém as outras nove colaboradoras revelam conformidade aos papéis a elas atribuídos no lar e no cuidado com os filhos, e, apesar de reclamarem do cansaço e do acúmulo de responsabilidades, algumas delas defendem a existência de atributos naturais especificamente masculinos e femininos, que as levam a executar melhor que os seus cônjuges algumas dessas tarefas.

É possível considerar que essas mulheres assumem uma postura de má-fé, alienando, até certo ponto, suas existências nos papéis que assumiram, realizando atividades que recusam seu sentido na objetividade de seus sexos. A mulher que reproduz os discursos que a oprimem não apenas usa da má-fé (Sartre, 1943/2015) como postura de alienação de sua responsabilidade com relação à própria existência, como também encarcera a si mesma na imanência de sua facticidade.

Mesmo considerando a educação sexista que muitas mulheres recebem, é importante ressaltar que a mulher é convocada à responsabilidade por sua existência concreta ao criticar as normas estabelecidas para o seu sexo, mas é à má-fé que ela recorre quando negligencia as possibilidades de desconstrução dos discursos naturalizantes e normatizadores que as oprimem.

Os resultados apresentados nesta investigação não pretendem, de nenhuma forma, representar a totalidade das experiências vividas pelas mulheres na conjugalidade contemporânea, porém representam um recorte que pode subsidiar a compreensão de como é vivida a situação de algumas mulheres no exercício dos papéis sociais a elas atribuídos. Permanecem então abertas as possibilidades de ampliação dos estudos fenomenológicos e sartrianos sobre a experiência vivida de mulheres na conjugalidade contemporânea.

\section{Referências}

Andrade, C. C., \& Holanda, A. F. (2010). Apontamentos sobre pesquisa qualitativa e pesquisa empírico-fenomenológica. Estudos de Psicologia, 27(2), 259-268. Recuperado em Junho de 2018, de: http://www.scielo.br/scielo.php?script=sci_arttext\&pid=S0103-166X2010000200013

Badinter, E. (1986). Um é o outro. São Paulo: Nova Fronteira.

Beauvoir, S. de (1970). Moral da Ambiguidade. Paz e Terra S.A. Rio de Janeiro. (Originalmente publicado em 1947).

Beauvoir, S. de (1949/2016a). O segundo sexo: Fatos e mitos (3a ed., Vol. 1, S. Milliet, Trad.) Rio de Janeiro: Nova Fronteira.

Beauvoir, S. de (1949/2016b). O segundo sexo: $A$ experiência vivida (3a ed., Vol. 2, S. Milliet, Trad.). Rio de Janeiro: Nova Fronteira.

Benevides, R. F. C. (2018). Tornar-se mulher: a experiência vivida na conjugalidade contemporânea sob uma perspectiva fenomenológico-existencial. (Dissertação de mestrado). Universidade de Fortaleza, Fortaleza.

Biroli, F. (2013, janeiro-abril). Autonomia, opressão e identidades: A ressignificação da experiência na teoria política feminista. Revista Estudos Feministas (Florianópolis), 21(1), 81-105. Recuperado em Junho de 2018, de: http://www.scielo. br/pdf/ref/v21n1/05.pdf

Castro, F. G. de, \& Ehrlich, I. F. (2016). Introdução à psicanálise existencial: Existencialismo, fenomenologia e projeto de ser. Curitiba: Juruá.

Connell, R., \& Pearse, R. (2015). Gênero: uma perspectiva global. São Paulo: NVersos.

Engel, M. (2009). Psiquiatria e Feminilidade. In M. Del Priori, \& C. Bassanezi (Orgs.), História das mulheres no Brasil (pp. 322-361). São Paulo: Contexto. 
Foucault, M. (1999). História da sexualidade I. A vontade de saber (M. T. da C. Albuquerque, \& J. A. G. Albuquerque, Trads.). Rio de Janeiro: Edições Graal.

Giddens, A. (1992). A transformação da intimidade: Sexualidade, amor \& erotismo nas sociedades modernas. São Paulo: Unesp.

Instituto Brasileiro de Geografia e Estatística (IBGE). (2014). Síntese de indicadores sociais: Uma análise das condições de vida da população brasileira. Recuperado em Junho de 2018, de http://biblioteca.ibge.gov.br/visualizacao/livros/liv91983.pdf

Madalozzo, R., \& Blofield, M. (2017, janeiro-abril). Como famílias de baixa renda em São Paulo conciliam trabalho e família. Revista Estudos Feministas (Florianópolis), 25(1), 215-240. doi: http:// dx.doi.org/10.1590/1806-9584.2017v25n1p215

Matos, M. I., \& Borelli, A. (2013). Espaço feminino no mercado produtivo. In C. B. Pinsky, \& J. M. Pedro (Orgs.), Nova história das mulheres no Brasil (pp. 126-147). São Paulo: Contexto.

Melo, D. M. P. de (2014). O corpo na gestalt-terapia: Um diálogo com Jean-Paul Sartre. (Dissertação de mestrado, Universidade de Fortaleza). Recuperado em Junho de 2018, de: http://bdtd.ibict. $\mathrm{br} /$ vufind/Record/UFOR_7e3516e3d95c72a24b441bb105b861cc

Miguel, L. F. (2017, setembro-dezembro). Voltando à discussão sobre capitalismo e patriarcado. Estudos Feministas (Florianópolis), 25(3) 1219-1237. doi: http://dx.doi.org/ $\underline{10.1590 / 1806-9584.2017 v 25 n 3 p 1219}$

Moore, H. (1997). Compreendendo sexo e gênero. Companion Encyclopedia of Anthropology. London: Routledge. Recuperado em Junho de 2018, de: https://edisciplinas.usp.br/pluginfile. $\mathrm{php} / 269229 / \mathrm{mod}$ resource/content $/ 0 /$ henrietta\%20moore\%20compreendendo\%20sexo\%20 e\%20g\%C3\%AAnero.pdf

Rago, M. (2009). Trabalho feminino e sexualidade. In M. Del Priori, \& C. Bassanezi (Orgs.), História das mulheres no Brasil (pp. 578-606). São Paulo: Contexto.

Ramos, R. L da S. (2015). Função da mulher na família: Uma crítica marxista. Problemata: $R$. Intern. Fil. 6(3), 129-145. doi: http://dx.doi. org/10.7443/problemata.v6i3.25383

Ranieri, L. P., \& Barreira, C. R. A. (2010). A entrevista fenomenológica. Anais do IV Seminário Internacional de Pesquisa e Estudos Qualitativos. Rio Claro, São Paulo.

Resolução $n^{o} 466$ (2012, 12 de dezembro). Resolve aprovar as diretrizes e normas regulamentadoras de pesquisas envolvendo seres humanos. Brasília, DF: Ministério da Saúde, Conselho
Nacional de Saúde. Recuperado em Junho de 2018, de http://bvsms.saude.gov.br/bvs/ saudelegis/cns/2013/res0466_12_12_2012.html

Sartre, J. P. (1978). O existencialismo é um humanismo; A imaginação; Questão de método (Seleção de textos de J. A. M. Pessanha; V. Ferreira, et al., Trad.). São Paulo: Abril Cultural.

Sartre, J. P. (2015). O ser e o nada: Ensaio de ontologia fenomenológica. Petrópolis, Rio de Janeiro: Vozes. (Originalmente publicado em 1943).

Sartre, J. P. (2016). O existencialismo é um humanismo. Petrópolis, Rio de Janeiro: Vozes. (Originalmente publicado em 1946).

Schneider, D. R. (2008). O Método Biográfico em Sartre: Contribuições do Existencialismo para a Psicologia. Estudos e pesquisas em psicologia (Rio de Janeiro), 8(2), 289-308. Recuperado em Junho de 2018, de: http://www.revispsi.uerj.br/ v8n2/artigos/pdf/v8n2a13.pdf

Triviños, A. N. S. (1987). Introdução à pesquisa em ciências sociais: A pesquisa qualitativa em educação. São Paulo, SP: Atlas.

Unbehaum, S. G. (2001). A desigualdade de gênero nas relações parentais: $\mathrm{O}$ exemplo da custódia dos filhos. In M. Arilha, S. G. Unbehaum, \& B. Medrado (Orgs.), Homens e masculinidades: Outras palavras (pp. 163-184). São Paulo: Editora 34.

Yalom, M. (2002). A história da Esposa, da Virgem Maria a Madonna: O papel da mulher casada dos templos bíblicos até hoje. Rio de Janeiro: Ediouro.

Rafaelle Fernanda Costa Benevides (Orcid: 00000003-2690-5783) é Mestre em Psicologia pela Universidade de Fortaleza - UNIFOR. Pós-graduada (MBA) em Gestão de Pessoas pela Faculdade 7 de setembro - FA7. Psicóloga graduada pela Universidade de Fortaleza - UNIFOR. Professora de Graduação e Pós-graduação na área de Gestão de Pessoas (RH). Email: rafaellebenevides@edu.unifor.br.

Georges Daniel Janja Bloc Boris (Orcid: 0000-00030726-1767) é psicólogo, mestre em educação e doutor em sociologia pela Universidade Federal do Ceará. Professor titular do Programa de Pós-Graduação em Psicologia da Universidade de Fortaleza. Coordenador do APHETO - Laboratório de Psicopatologia e Psicoterapia Humanista-Fenomenológica Crítica. Psicoterapeuta, supervisor de estágio em psicologia clínica e formador de psicoterapeutas em GestaltTerapia. E-mail: geoboris@uol.com.br 